\title{
Lecciones tempranas de un maestro también de Literatura Hispanoamericana
}

\author{
José Carlos Rovira Soler ${ }^{1}$
}

Recibido: 17 de abril de 2017 / Aceptado: 4 de octubre de 2017

Resumen. Alonso Zamora Vicente fue precursor de estudios sobre Julio Cortázar (1953) o sobre César Vallejo (1957), en un tiempo en el que el primero no era aún quien fue, ni el segundo era casi conocido ni tenido en cuenta por la crítica académica en España. Se muestra aquí el interés por el poeta peruano en quien luego fue máximo especialista Roberto Paoli, lector en Salamanca en los años en los que Zamora Vicente escribía sobre Vallejo; así como la dirección de la primera Tesis Doctoral en España sobre el peruano. Se recuerda la amistad de Zamora Vicente con Julio Cortázar, con Jorge Luis Borges (junto con sus distancias), su interés por Rubén Darío, la dirección de la Tesis Doctoral de Vargas Llosa sobre García Márquez, su labor editorial americanista con tantos autores americanos replanteados por Alonso Zamora en España. Se rescata, en definitiva, la lección cultural de quien fue maestro en disciplinas lingüísticas y literarias entre las que estuvieron las que procedían de su pasión por Hispanoamérica.

Palabras clave: Alonso Zamora Vicente; Julio Cortázar; César Vallejo; Edición; Hispanoamérica en España.

\section{[en] Early lessons from a mentor in Hispanic American literature}

\begin{abstract}
Alonso Zamora Vicente was a precursor of works on Julio Cortázar (1953) or César Vallejo (1957) when the former was not yet the celebrated writer he would become later, and the latter was scarcely known in Spain or taken into consideration by academic critics. This article highlights the importance that his interest in César Vallejo had for Roberto Paoli, who was a foreign language teacher in Salamanca when Zamora Vicente started writing about César Vallejo, and later would become a top expert on the poet's work. Likewise, Zamora Vicente was tutor of the first $\mathrm{PhD}$ thesis in Spain about this writer. His friendship with Julio Cortázar and Jorge Luis Borges (and his differences with the latter), his keen interest in Rubén Darío, his role as a tutor of Vargas Llosa's thesis about García Márquez and his renewing editorial work around American literature are also discussed. In conclusion, his wide knowledge of linguistic and literary disciplines directly related to his passion for Hispanic America is recalled, reassessing the inspiring cultural lessons he offered.
\end{abstract}

Keywords: Alonso Zamora Vicente; Julio Cortázar; César Vallejo; editorial works, Hispanic America.

Sumario: 1. Presentación; 2. Alonso Zamora Vicente, pionero en la crítica hispanoamericana contemporánea: Julio Cortázar; 3. "Considerando, comprendiendo" y otros poemas de César Vallejo; 4. Roberto Paoli, discípulo de Zamora Vicente; 5. El testimonio de Francisco Martínez García; 6. Hay muchas más lecciones: una enumeración que pretende no ser caótica; 7. Referencias bibliográficas.

$1 \quad$ Universidad de Alicante

Email: rovi@ua.es 
Cómo citar: Rovira Soler, J. C (2017). Lecciones tempranas de un maestro también de literatura hispanoamericana, en Revista de Filología Románica 34.Núm. especial, 203-210.

\section{Presentación}

Cuando se me invitó a hablar en este recuerdo de los cien años del nacimiento del maestro Alonso Zamora Vicente, opté, en función de mi dedicación profesional, por hacerlo sobre don Alonso y la literatura hispanoamericana. Sabía, claro, que algunos colegas y queridos amigos, como el desaparecido Luis Sáinz de Medrano, abordaron el tema con rigor, y conocía yo, además, recuerdos y testimonios de personas que convivieron con él tiempos y literaturas vividos en América y siempre sobre Hispanoamérica. También la reconstrucción imprescindible, biobibliográfica, de Mario Pedrazuela era una guía para tantos temas y sobre todo personas, por lo que deduje que, si podía decir algo nuevo aquí, sería en función de engarzar un recorrido crítico de don Alonso a unos recuerdos personales que siempre están muy presentes. Si consigo explicarme sabrán porqué.

\section{Alonso Zamora Vicente, pionero en el interés por la literatura hispanoamericana contemporánea: Julio Cortázar}

Recuerdo una mañana invernal de 1970 en que en el bar del edificio B de la Facultad de Filosofía y Letras, hoy Facultad de Geografía e Historia, coincidí con el profesor Zamora Vicente. Eran entre las nueve o las diez de la mañana y me invitó a un café en una mesa de aquel lugar. Unos días antes me había presentado a él el profesor Manuel Gil Esteve y yo, que con el temor de que me preguntase sobre dialectología mantenía un silencio tímido y temeroso, obtuve sin embargo una pregunta directa sobre mis lecturas recientes y una sonrisa entre inquieta e interrogante. $\mathrm{Me}$ preguntó qué había leído en los últimos meses; con timidez le respondí que había leído Rayuela de Julio Cortázar. Sonrió y con toda la humildad de lector atento que siempre tuvo me afirmó que conocía a Cortázar y que hacía ya tiempo que le interesaba y mucho como escritor. No me recordó en ese momento que, en 1953, había sido de los primeros en publicar una reseña crítica sobre quien, en 1963, había dado a la luz aquella obra que cinco años después se convirtió para mí en devoción de juventud.

Conocí luego, bastante después, un artículo que don Alonso había publicado diez años antes de la aparición de aquella novela que nos seducía: "Tres nombres argentinos", publicado, en 1953, en los Quaderni Ibero Americani de Giovanni Maria Bertini. Hablaba allí de Daniel Devoto, de Alberto María Salas y, en primer lugar, de Julio Cortázar. Los párrafos que le dedica a éste son premonitorios desde el comienzo: "Cuando escribe, parece que deja caer las palabras pesadamente, frenadas, y luego las abandona con cierto ritmo lento, temeroso de que se hagan daño al tropezar con el bajo suelo" (Zamora Vicente 1953:321). Tras mencionar Los reyes, de 1949, se centra en Bestiario, aparecido en 1951, y comenta sobre todo el último relato de esta obra, tras una valoración general: 
Lo importante es el indudable vértigo, el escalofrío ante las posibles situaciones. Cada cuento de Bestiario es un alocado luchar con una serie de fuerzas, ignoradas pero presentes, que viven silenciosas el dorso de la real peripecia. Son diálogos con la sombra, con el trasmundo más cercano, el que puebla nuestra propia casa, nuestro inesperado dolor de cabeza, nuestro pobre viaje en autobús, tarde de domingo al aire, las tapias del cementerio en el camino (Zamora Vicente 1953).

Resalto y recuerdo párrafos porque creo que son, como he dicho, muy importantes para comprender aquel mundo que don Alonso, en Buenos Aires, había entendido entre los primeros. El comentario del relato que da título a la obra es notable: la extrañeza cotidiana del tigre que puebla la casa creando sensaciones que no descubrimos hasta que estallan en medio de bestiarios de hormigas, insectos, mamboretá verde...y sensaciones que nos hacen percibir a la fiera, casi verla "en la oscura vivencia de la no-vida". Un enigma entre lo cotidiano y lo fantástico que tiene mucho que ver, como planteó la crítica, con lecturas con las que Alonso Zamora podía superar el costumbrismo y realismo de sus Primeras hojas con la entrada a lo fantástico que inicia con Smith y Ramírez, S. A. (1957). El papel de la lectura de Julio Cortázar, aparte de las marcas de Franz Kafka y de James Joyce, en aquella obra no genera sólo un caso afortunado de juicio crítico sino, sobre todo, una huella literaria que perdurará en quien fue también un gran creador.

En el interior de aquel trabajo, dos observaciones sobre el lenguaje se me hacen muy relevantes ahora. Señala don Alonso que "no importa [...] que la andadura sintáctica no sea la ortodoxa (o la consagrada, mejor)" y, más adelante, afirma que todo se dice

con una prosa excelente, donde el pulimento del idioma no desdeña, de cuando en cuando, la expresión de auténtico valor criollo. Creo que un libro como Bestiario está destinado a ser un episodio muy destacado en la historia del español escrito. Por lo que dice y por cómo lo dice (Zamora Vicente 1953).

Son detalles anticipadores de una posición que entendimos a través de él: fue también de los primeros, en una retardataria Academia a la que llegó en 1966, en entender lo que era ese español de América, que conoció vivencialmente en su estancia argentina y mexicana de fines de los cuarenta y primeros años del decenio siguiente, y tantas veces más, $\mathrm{y}$, literariamente, a lo largo de toda su vida. Si pudiera ampliar la reflexión ahora les indicaría que la lectura de la edición que Zamora hizo de Tirano Banderas fue la mejor lección que recibía en una época de ese español de América que Valle Inclán recreó en su obra.

\section{3. "Considerando, comprendiendo" y otros poemas de César Vallejo}

En mayo de 2002 tuve el honor de realizar la laudatio de Don Alonso en su nombramiento como Doctor Honoris Causa por la Universidad de Alicante. Entre múltiples incitaciones que él había construido para nosotros, los que fuimos sus discípulos, recordé una que me sigue pareciendo pertinente. Dije para evocar los años finales de los sesenta: 
Un artículo suyo, recuerdo, nos resultó muy atractivo. Estudiábamos en la cansina Facultad de Letras de la Complutense la Literatura Hispanoamericana en los rancios volúmenes de Raimundo Lazo y además no llegábamos nunca al siglo XX. Recuerdo la lectura de un artículo de Zamora, "Considerando, comprendiendo", que nos ponía delante a un poeta que necesitábamos en ese tiempo, el peruano César Vallejo en uno de sus poemas más emblemáticos. La lección de Zamora Vicente nos reafirmaba la fuerza de una lengua que, con la lectura del poeta, ya habíamos presentido. Me refiero por tanto a su capacidad para ofrecer lo que estábamos buscando los más jóvenes (Rovira Soler 2002).

Y es absolutamente verdad y hoy quiero reafirmarme en ello. Allá por los veinte años, es decir en 1969, empezábamos a conocer a César Vallejo y algunos supimos que era una devoción importante para aquel profesor (aunque para otros muchos no, pues era hasta un profundo desconocido), que entendía que su mundo literario lo poblaban gentes que "pueden probar documentalmente que han nacido pequeñitos", como decía en 1969 hablando de su propia escritura (Zamora Vicente 1969). El recuerdo de César Vallejo tiene dos límites temporales de publicación: 1957 con "Considerando, comprendiendo" en el que como notas a un poema comentó aquel que comienza "Considerando en frío, imparcialmente / que el hombre es triste, tose y, sin embargo / se complace en su pecho colorado" (Zamora Vicente 1957), y 1973, en el homenaje de Cuadernos hispanoamericanos a Dámaso Alonso, en el que con el título de "Una página de Poemas humanos" comenta aquel que inicia "Me viene hay días una gana ubérrima, política / de querer, de besar al cariño en sus dos rostros" (Zamora Vicente 1973). Si el primero es un análisis de la estructura de considerar y comprender donde el ser humano, ("que lo único que hace es componerse de días"), es considerado y comprendido, y tras mirar con lentes "aquel certificado / que prueba que nació muy pequeñito", es llamado con una seña para que se acerque y para darle un abrazo "emocionado", en palabra reiterada tres veces, "que tiene ya un eco de lágrimas" y tiene por testigo a toda la Humanidad, como insistía don Alonso; el segundo es una reflexión amplia, estructural y esencial sobre el uso del verbo querer, para construir situaciones que van del desamparo social a la de remedios "contra la radical soledad humana".

Una lección también fueron aquellos artículos pertenecientes a lo que en la práctica docente y didáctica llamamos, o llamábamos, "Comentario de texto". Como profesor de bachillerato durante muchos años agradecí a don Alonso (y a algunos pocos más) su disposición a hablar sobre el significado, las estructuras rítmicas, la organización semántica, la construcción retórica, de poemas y textos concretos de Vallejo y de tantos otros. Diré algo más adelante sobre esto.

\section{Roberto Paoli, discípulo de Zamora Vicente}

Hablaba antes del artículo de Zamora Vicente publicado en 1957 sobre César Vallejo y digo ahora que, hasta ese año, que yo sepa, sólo se había dedicado al estudio del peruano, en España, José María Valverde, en 1949 -aparte, por supuesto de Juan Larrea desde el exilio y algunas contribuciones de la época en las que César Vallejo estuvo en España, entre ellas las de José Bergamín y Wenceslao Fernández Flores (hay también una edición de quince poemas (Cartagena, Baladre, 1948), realizada por José Escobar y Eugenio Martínez, y otra antología breve publicada en Gra- 
nada en 1953 por José Jiménez Blanco; también la referencia, en 1949, de la revista Espadaña (como nos ha recordado Antonio Viudas, recientemente, a través del artículo de Francisco Martínez García sobre la recepción del peruano en España, de 1992). El artículo de don Alonso, publicado como ya he dicho en Venezuela, forma parte entre nosotros de unos precedentes bibliográficos que luego, afortunadamente, se fueron ampliando y mucho.

El año de la publicación del artículo de Zamora llegaba a Salamanca como lector de italiano un joven que contaba 27 años y que ya había publicado en Italia algunas traducciones de poetas españoles recientes. Conocí a Paoli en 1974 en Florencia en una mañana en la que al entrar en su clase él estaba recitando "Zumban las balas en la tarde última. / Hay viento y hay cenizas en el viento, /se dispersan el día y la batalla deforme, / y la victoria es de los otros", el comienzo del "Poema conjetural" de Jorge Luis Borges, con el que iniciaba un curso monográfico realmente excelente sobre el argentino. Como sabemos todos, Paoli fue el máximo especialista y traductor italiano del autor peruano y me he planteado estos días el papel que pudo tener don Alonso en aquel descubrimiento. Paoli debió llegar a Salamanca en septiembre de 1957, año del primer artículo sobre Vallejo, y permaneció con don Alonso tres cursos. Sobre el significado de Paoli, don Alonso fue siempre rotundo: "y no dejes de ver a quien hace veinte años y durante tres fue mi fue mi lector de italiano en Salamanca, Roberto Paoli. Es lo mejor de lo nuestro en aquella Universidad", me decía en una carta de octubre de 1974. No en vano, en su tiempo salamantino, Paoli se dedicó a poetas españoles e inició algunas pasiones duraderas como la poesía de Miguel de Unamuno, que tradujo y publicó en una excelente edición, o a Lope de Vega, como referente que también nos lo vincula a Zamora Vicente. Fallecido Paoli en 2000 nunca pude preguntarle, aunque lo vi varias veces, sobre el papel de don Alonso en su formación hispanoamericanista y aclarar los orígenes de su pasión vallejiana que, en 1964, se concretaba ya en la primera traducción de Poesie, aparecida en Lerici de Milán con más de doscientas páginas de introducción, por lo que queda aquí como una coincidencia más, significativa, entre un maestro y quien fuera su discípulo.

\section{El testimonio de Francisco Martínez García}

Antonio Viudas nos ha recordado, recientemente, en su correspondencia continua por los cien años del maestro Alonso Zamora, la tesis doctoral de Francisco Martínez García, fallecido hace varios años y catedrático de la Universidad de León. La tesis sobre César Vallejo fue defendida en la Universidad Complutense a fines de los sesenta y tuvo un recuerdo por parte de su autor que sintetizo a partir de su artículo sobre "la recepción de Vallejo en España". Contaba Martínez García:

Tenía yo que realizar mi memoria de licenciatura. Y la hice sobre la poesía de César Vallejo. Luego de recibir un consejo eficaz, me propuse hacer la tesis doctoral sobre el mismo tema. Aquí la cosa resultó un tanto difícil, hasta que encontré a un hombre, Alonso Zamora Vicente, Secretario Perpetuo de la Real Academia Española y catedrático en la universidad de Madrid, que se avino a dirigírmela. Recuerdo que yo asistía a los cursos de doctorado, en la universidad Complutense. Dictaba uno de los cursos Zamora Vicente. Nos reunía en torno a una amplia mesa de la biblioteca del Departamento, con- 
tigua a su despacho, en el edificio B de Filosofía y Letras de la Complutense. Allí estaba entonces, con toda su gracia eficaz, Sabina de la Cruz, esposa de Blas de Otero. Cierto día, con el humor tan peculiar que derrochaba, se me queda mirando fijamente don Alonso, repentinamente parado en su discurso. Éramos unos ocho o diez. Se me queda mirando y me dice: "Así que usted quiere hacer una tesis sobre Vallejo", Contesto: "Sí, señor". Guarda un silencio casi imperceptible y pregunta a los alumnos que rodean la mesa: “¿Quiénes de ustedes han leído a Vallejo?”. Nadie responde. Se queda un tantico cortado y sorprendido, pero apenas si se le nota. Repuesto, dice tan sólo, con su humor de siempre, esta vez quizás un poquito más amargo: "Pues, léanlo, que es muy higiénico" (Martínez García 1992:15).

\section{Hay muchas más lecciones: una enumeración que pretende no ser caótica}

En 2016, para conmemorar el centenario de Rubén Darío, decidí que en mi Universidad se realizara un seminario con amplia participación sobre "Textos esenciales de Rubén Darío”. Bueno, decidí no, decidimos, porque allí se resuelve en conjunto por aquel enunciado que algunos aprendimos que había que hacer "todo entre todos". En 2018, el seminario será "Textos esenciales de César Vallejo", para conmemorar el centenario de Los heraldos negros y los 80 de la muerte del poeta peruano. Cuento esto porque con un querido colega hemos convenido que si centramos en textos las intervenciones nuestras y las solicitadas evitaremos que algunos congresos sobre autores muy transitados tengan como subtítulo la dirección necesaria o el deambular probable "Por los cerros de Úbeda". Esta actividad me ha venido aquí porque en aquel seminario era muy difícil no recordar en aquellos comentarios textuales el modelo de análisis que don Alonso realizó de "Divagación" de Rubén Darío (Zamora Vicente 1973b), o del proceso de escritura de "Cosas del Cid" (Zamora Vicente 1973a), dos poemas de Prosas profanas que tienen un magistral asedio, siendo el segundo, a través del manuscrito que estaba en poder de los herederos de Alejandro Sawa, un patrón didáctico de eso que hemos llamado, teóricamente, crítica genética. Sobre Rubén Darío y don Alonso tengo algún recuerdo personal. Le llevé, en 2005, a su casa de San Sebastián de los Reyes una edición mía conmemorativa del centenario de Cantos de vida y esperanza. Nos reímos ante el disparatado cisne que una conocida editorial había puesto en portada. Hablamos ese día mucho de Rubén, y en un momento recitó con naturalidad grave aquello de "Seguramente Dios te ha conducido / para regar el árbol de mi fe, / hacia la fuente de la noche y del olvido, / Francisca Sánchez, acompáñame...”.

Ha reconstruido muy bien Mario Pedrazuela momentos de la relación de Alonso Zamora con Jorge Luis Borges, al que admiraba, iniciada en Buenos Aires y continuada durante muchos años. Analizó muy bien Luis Sáinz de Medrano ${ }^{2}$ el significado de Borges para don Alonso, por lo que no reitero ahora una relación y un significado ya tratado. Me queda un recuerdo personal. En 1990, en una antología sobre identidad cultural latinoamericana, introduje en los espacios sobre identidad lingüística un conocido texto de Borges, "Las alarmas del doctor Américo Castro", que, don Alonso, había vivido en una conferencia en Buenos Aires, en 1951 en la

2 Por ejemplo, Sáinz de Medrano (2003). 
que Borges lo leyó. El texto lo comentó luego con una fuerte distancia crítica varias veces. En 1986, en "Borges, esa ficción”, el artículo que publicó en su muerte, volvió sobre el episodio y valoró que Américo Castro en La peculiaridad lingüistica rioplatense y su sentido histórico, las páginas que Borges contestaba como "alarmas" haciéndolo "con acritud y brillo" -según valoraba Zamora-, quien seguía afirmando que lo hacía "aunque no supiera ver exactamente las razones últimas del filólogo español", quien "ponía en discusión su Buenos Aires querido, sacaba a relucir, quizá, el final regusto del tango y la milonga y la indiscutible pesantez de la inmigración", por lo que "Borges no supo ver lo que había detrás de esas palabras". Una polémica que debía ser lingüística, sobre lunfardismos y otras cuestiones de lengua, Jorge Luis Borges la convirtió en una burla y, por eso, al ver el texto en mi antología amplió en carta personal su valoración del texto de Borges, que decía don Alonso "rezumaba un poquillo de mala idea antiespañola", concluyendo sin embargo con algo que, de alguna forma, justificaba al argentino al afirmarme en aquella carta que, claro, la culpa la habían tenido los (y citaba algunos nombres que yo ahora, lógicamente, omito) "y otros memos que el Instituto de Cultura Hispánica había puesto a pasear por toda Hispanoamérica. ¿Qué visión podía tener Borges de la cultura española a través de ellos?"

Hay muchos otros espacios hispanoamericanistas que ya no puedo recorrer aquí. Me hubiera gustado reconstruirles momentos en el que don Alonso tuvo a alumnos como aquel Mario Vargas Llosa, que se doctoró en la Complutense, en 1971, con Gabriel García Márquez, historia de un deicidio. Me hubiera gustado también reconstruir la labor editorial americanista de don Alonso en Castalia con las ediciones de Vallejo, Neruda, Bioy Casares, Güiraldes, Marechal, Parra, Mistral, Quiroga... tantos nombres que fueron una de las visiones más sistemáticas editoriales de clásicos contemporáneos en España. Me hubiera gustado, también, comentar sus ediciones de americanos, la de Domingo Faustino Sarmiento por ejemplo y sus Recuerdos de Provincia (Oasis, México, 1963), y la de clásicos españoles en México, y me hubiera dirigido también a otros puntos de su interés a los que me incitó y no pude realizar. Recuerdo, por ejemplo, a Rómulo Gallegos como indicación precisa. Hay por tanto muchas notas dispersas que, ojalá, un día organice y resuelva en una publicación sobre quien, como he intentado decir, se anticipó a muchas cosas y leyó como casi nadie a contemporáneos que ya son clásicos.

\section{Referencias bibliográficas}

Martínez García, Francisco (1992): "La recepción de Vallejo en España". Cuadernos Hispanoamericanos 502:7-20.

Rovira Soler, José Carlos (2002): “Laudatio pronunciada por el Sr. D. José Carlos Rovira Soler con motivo de la investidura como Doctor Honoris Causa por la Universidad de Alicante del Excmo. Sr. D. Alonso Zamora Vicente", in Solemne Acto de Investidura como Doctor Honoris Causa del Excelentísimo señor D. Alonso Zamora Vicente, disponible en https://web.ua.es/es/protocolo/documentos/eventos/honoris/zamora-vicente-alonso-2002/laudatio-de-alonso-zamoravicente.pdf [consulta 21/11/2017].

Sáinz de Medrano, Luis (2003): "Zamora Vicente y la literatura hispanoamericana", in C. Alemany Bay et al (eds.), Con Alonso Zamora Vicente (Actas del Congre- 
so Internacional "la Lengua, la Academia, lo Popular, los Clásicos, los Contemporáneos...), vol. I, pp. 223-230. Alicante: Universidad de Alicante.

Zamora Vicente, Alonso (1953): "Tres nombres argentinos". Quaderni Ibero Americani 2:321-323.

Zamora Vicente, Alonso (1957): “Considerando, comprendiendo (Notas a un poema de César Vallejo)". Cultura Universitaria 60, marzo-abril: 80-87.

Zamora Vicente, Alonso (1969): "Yo escribo los domingos", in F. Ynduráin (ed.), Prosa novelesca actual. Segunda reunión, agosto 1968, pp. 284-285. Madrid: Ministerio de Educación y Ciencia, Dirección General de Enseñanza Superior e Investigación.

Zamora Vicente, Alonso (1973): "Una página de Poemas humanos". Cuadernos Hispanoamericanos 280-282:579-587.

Zamora Vicente, Alonso (1973a): "Un manuscrito de Rubén Darío", in AA.VV., Homenaje a la memoria de Antonio Rodríguez Moñino (1910-1970), pp. 637649. Madrid: Castalia.

Zamora Vicente, Alonso (1973b): "Divagación": aclaración sobre el modernismo", in AA.VV., El comentario de textos, pp. 167-193. Madrid: Castalia.

Zamora Vicente, Alonso (1986): “Borges, esa ficción”. Ínsula 479:5-6. 